\title{
Review Article \\ Infections Caused by Actinomyces neuii: A Case Series and Review of an Unusual Bacterium
}

\author{
Nathan Zelyas, ${ }^{1}$ Susan Gee, ${ }^{1}$ Barb Nilsson, ${ }^{2}$ Tracy Bennett, ${ }^{3}$ and Robert Rennie ${ }^{1}$ \\ ${ }^{1}$ Provincial Laboratory for Public Health, Walter Mackenzie Health Sciences Centre, University of Alberta Hospital, 8440-112 Street, \\ Edmonton, AB, Canada T6G 2J2 \\ ${ }^{2}$ Queen Elizabeth II Hospital, 10409-98 Street, Grande Prairie, AB, Canada T8V $2 E 8$ \\ ${ }^{3}$ Red Deer Regional Hospital, 3942-50a Avenue, Red Deer, AB, Canada T4N 4E7
}

Correspondence should be addressed to Nathan Zelyas; nzelyas@ualberta.ca

Received 24 July 2015; Accepted 28 December 2015

Copyright (c) 2016 Nathan Zelyas et al. This is an open access article distributed under the Creative Commons Attribution License, which permits unrestricted use, distribution, and reproduction in any medium, provided the original work is properly cited.

\begin{abstract}
Background. Actinomyces neuii is a Gram-positive bacillus rarely implicated in human infections. However, its occurrence is being increasingly recognized with the use of improved identification systems. Objective. To analyse A. neuii infections in Alberta, Canada, and review the literature regarding this unusual pathogen. Methods. Cases of A. neuii were identified in 2013-2014 in Alberta. Samples were cultured aerobically and anaerobically. A predominant catalase positive Gram-positive coryneform bacillus with no branching was isolated in each case. Testing was initially done with API-CORYNE ${ }^{\circledR}$ (bioMérieux) and isolates were sent to the Provincial Laboratory for Public Health for further testing. Isolates' identities were confirmed by matrix-assisted laser desorption ionization time-of-flight mass spectrometry microbial identification system (MALDI-TOF MS MIS; bioMérieux) and/or DNA sequencing. Results. Six cases of A. neuii infection were identified. All patients had soft tissue infections; typically, incision and drainage were done followed by a course of antibiotics. Agents used included cephalexin, ertapenem, ciprofloxacin, and clindamycin. All had favourable outcomes. Conclusions. While A. neuii is infrequently recognized, it can cause a diverse array of infections. Increased use of MALDI-TOF MS MIS is leading to increased detection; thus, understanding the pathogenicity of this bacterium and its typical susceptibility profile will aid clinical decision-making.
\end{abstract}

\section{Introduction}

Members of the genus Actinomyces are the commonest cause of the oft-described disease, actinomycosis. This clinical syndrome is characterized by its chronic course, the invasion of multiple tissue planes, the formation of sinus tracts and masses resembling malignancy, the production of "sulfur granules," and its relapsing nature when short courses of antimicrobials are used [1-3]. Although actinomycosis typically involves cervicofacial, thoracic, and abdominal regions, Actinomyces species can cause a variety of infections, including abscesses and skin infections in various locations [4-6], ocular infections [5], urinary tract infections $[4,6]$, genital infections $[4,6]$, intrauterine contraceptive device infections $[5,7]$, appendicitis [4], cholecystitis [4], osteomyelitis $[5,6]$, bacteremia [4-6], endocarditis [8, 9], CNS infections [10-13], and many others [14].

Organisms belonging to the Actinomyces genus are typically aerotolerant Gram-positive rods that grow in branching filaments. Isolates are usually catalase and urease negative,
CAMP negative, and nonpigmented and produce succinic and lactic acid as major end products of metabolism [15]. However, not all Actinomyces species share all of these characteristics, and one of these is the clinically relevant Actinomyces neuii.

Prior to 1994, A. neuii isolates were classified as members of CDC (Centers for Disease Control) fermentative coryneform group 1 or group 1-like $[16,17]$. These isolates were common in that they were Gram-positive coryneform rods, nonmotile, catalase positive, urease negative, esculin hydrolysis negative, CAMP positive, and fermented glucose, maltose, sucrose, mannose, and xylose [16, 17]. Sequencing of the 16S rRNA genes of CDC coryneform group 1 and group 1-like isolates revealed that they are closely related subspecies belonging to the Actinomyces genus: A. neuii subsp. neuii and A. neuii subsp. anitratus [18]. The term "neuii" was chosen to honour Dr. Harold Neu, a well-known physician of infectious diseases; "anitratus" was chosen to reflect the lack of nitrate reduction by A. neuii susp. anitratus [18]. 
Since its classification, $A$. neuii has been implicated in a number of human infections [19]. However, due to its unusual laboratory characteristics, isolates have likely been dismissed as members of the Corynebacterium genus and its occurrence in clinical specimens is probably underreported. Indeed, the use of advanced bacterial identification systems, such as matrix-assisted laser desorption ionization time-offlight mass spectrometry microbial identification systems (MALDI-TOF MS MIS), in clinical laboratories will likely result in an increased frequency of correctly identifying bacteria that were previously difficult to identify using traditional phenotypic methods [20, 21]. Because of the increasingly widespread use of MALDI-TOF MS MIS, understanding the significance of isolating previously underrecognized pathogens is important in guiding laboratory reporting and clinical practices.

The present study examines cases of $A$. neuii infections detected in several community and tertiary care laboratories and confirmed by a reference microbiology laboratory. The literature regarding $A$. neuii infections is reviewed and compared to the findings in this series of cases.

\section{Methods}

Clinical specimens were submitted to local microbiology laboratories during 2013-2014 in Alberta, Canada. Samples were initially examined microscopically after Gram staining and cultured aerobically and, if deemed appropriate, anaerobically on typical culture media including sheep blood agar, brain heart infusion agar, and phenylethyl alcohol agar (Dalynn Biologicals Inc., Calgary, Alberta). Isolates were initially identified by producing characteristic convex, circular, smooth, and white colonies with entire edges with consistent Gram stain appearance, catalase reaction, and major acid end-product profiles as determined by gas-liquid chromatography. If the specimen was submitted and initially worked up by a local microbiology laboratory, isolates suspected of being $A$. neuii were further identified using the API-CORYNE (bioMérieux, France) test strip. Further confirmation of isolates' identities was performed at the Alberta Provincial Laboratory for Public Health, Edmonton, Alberta, using the VITEK ${ }^{\circledR}$ MS MALDI-TOF MS MIS (bioMérieux, France) and/or 16S rRNA gene sequencing. The VITEK MS MALDI-TOF MS MIS assay was carried out according to the manufacturer. The in vitro diagnostic database used for comparing spectra was VITEK MS v2.0 Knowledge Base (bioMérieux, France); matches with a $\geq 99.9 \%$ confidence were accepted as $A$. neuii.

In order to carry out the sequencing of a portion of the $16 \mathrm{~S}$ rRNA gene, genomic DNA was extracted using a pure culture of organism growing on sheep blood agar incubated anaerobically at $35^{\circ} \mathrm{C}$. A sweep of organism was

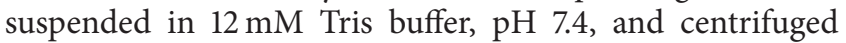
at $13,000 \times \mathrm{g}$ for 3 minutes. The pellet was resuspended in rapid lysis buffer (100 mM NaCl; $10 \mathrm{mM}$ Tris- $\mathrm{HCl}, \mathrm{pH} 8.3$; $1 \mathrm{mM}$ EDTA, $\mathrm{pH} 9.0 ; 1 \%$ Triton $\mathrm{X}-100)$ and subjected to three freeze/thaw cycles of $-80^{\circ} \mathrm{C}$ for 15 minutes followed by complete thawing. This preparation was then boiled for 15 minutes, cooled to room temperature, and centrifuged at $13,000 \times \mathrm{g}$ for 15 minutes. Nucleic acid in the supernatant was used for conventional polymerase chain reaction (PCR) with the following previously described 16S rRNA gene primers: 16S-F 5'AGA GTT TGA TCA TGG CTC AG 3' and 16S-R 5'GGA CTA CCA GGG TAT CTA AT 3' [46]. Amplification reactions were carried out using Platinum ${ }^{\circledR}$ Pfx DNA Polymerase (Thermo Fisher Scientific, Waltham, MA, USA) according to the manufacturer with the following cycling conditions: $94^{\circ} \mathrm{C}$ for 2 minutes, then 25 cycles of $94^{\circ} \mathrm{C}$ for 15 seconds, $50^{\circ} \mathrm{C}$ for 30 seconds, and $68^{\circ} \mathrm{C}$ for 20 seconds. After product cleanup and quantification with the ChargeSwitch $^{\circledR}$ Kit and the NanoDrop ${ }^{\text {TM }} 2000$ (Thermo Fisher Scientific), respectively, DNA sequencing was performed using the BigDye ${ }^{\circledR}$ Cycle Sequencing and BigDye XTerminator $^{\mathrm{TM}}$ Purification Kits (Thermo Fisher Scientific) on the Applied Biosystems ${ }^{\mathrm{TM}}$ 3500xL Genetic Analyzer (Thermo Fisher Scientific). Sequence data was viewed and edited using the BioEdit program and uploaded to the Ribosome Database Project to obtain sequence matches [47]. All but one of the sequences obtained were over 350 nucleotides; despite multiple attempts, one amplicon yielded only 257 nucleotides of high quality sequence (see Supplementary Data in the Supplementary Material available online at http://dx.doi.org/10.1155/2016/6017605). In each case, a seqmatch (S_ab) score of 1.000 (signifying $100 \%$ identity) was found with at least one other submitted $A$. neuii rRNA gene nucleotide sequence. Identification to the subspecies level was not performed.

Susceptibility testing was carried out using gradient diffusion Etest ${ }^{\circledR}$ strips (bioMérieux, France) under the conditions described for anaerobic organisms by the Clinical and Laboratory Standards Institute (CLSI; [48]). Briefly, a $0.5 \mathrm{McFarland}$ suspension of organism was inoculated onto Anaerobic Laked Blood Agar (Dalynn Biologicals Inc.) and incubated at $36^{\circ} \mathrm{C}$ anaerobically for 48 hours. Minimal inhibitory concentrations (MICs) were determined as per the manufacturer's instructions. Breakpoints were interpreted as per CLSI guidelines for anaerobic bacteria [48]. Patient information was obtained from specimen requisitions and the treating physicians. The work described in this paper does not require ethics review as defined in Section 2.4 of the Tri-Council Policy Statement: Ethical Conduct for Research Involving Humans [49].

\section{Results}

Actinomyces neuii was isolated from eight patients from February 2013 to July 2014; patient information was available for six of these cases (Table 1). From each patient, a predominant Gram-positive, catalase positive coryneform bacillus was isolated. Gas chromatography revealed a major succinic acid peak for the isolates. In all three cases where the isolate was initially worked up by a local laboratory, the API-CORYNE test strip correctly identified the organism as $A$. neuii. The first five isolates were confirmed as $A$. neuii using 16S rRNA gene sequencing; this allowed the laboratory's VITEK MS MALDI-TOF MS MIS instrument to be validated for identifying $A$. neuii and therefore be used without further extensive confirmatory testing. Patient 


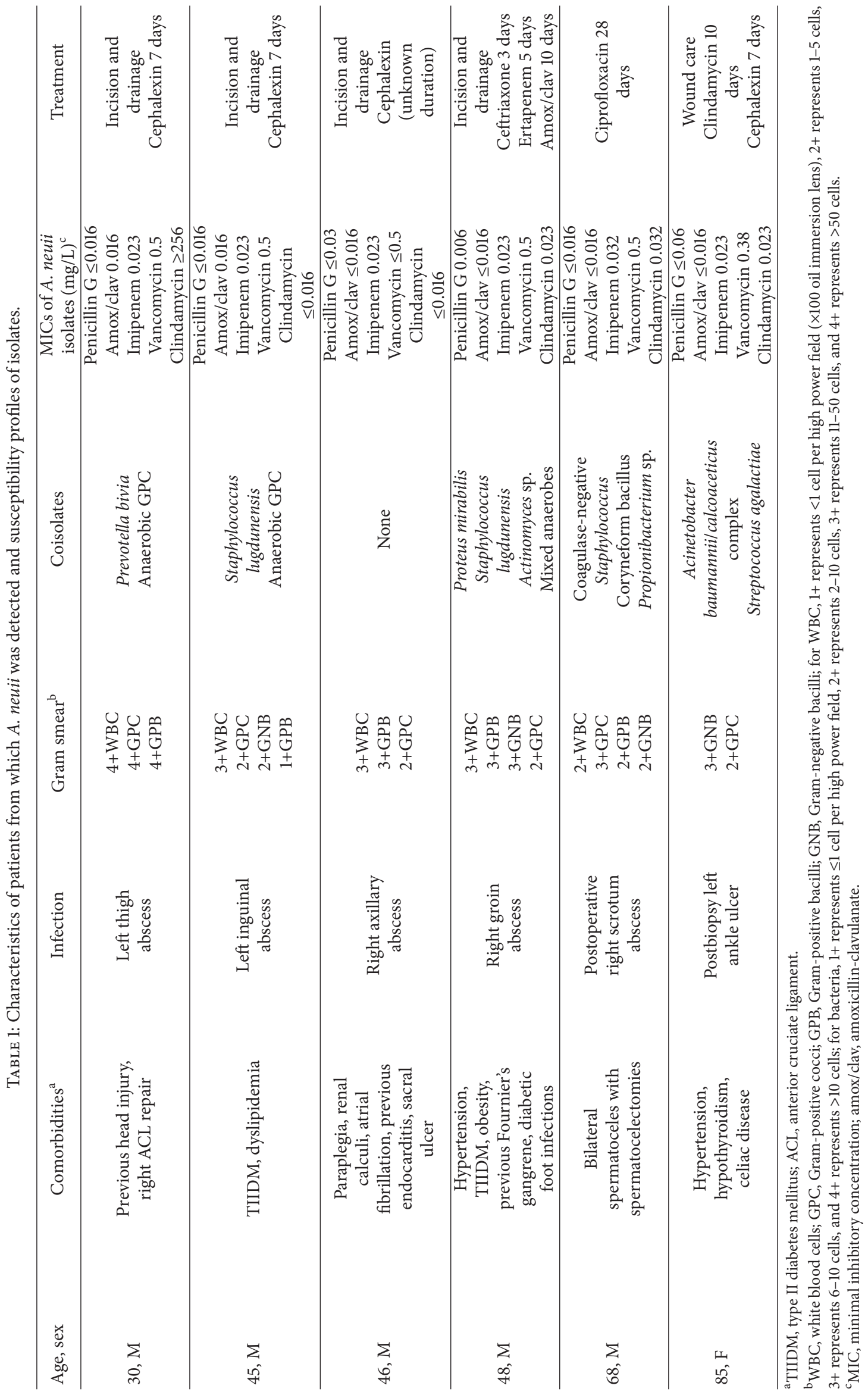


ages ranged from 30 to 85 years; all but one of the patients were male. There was no obvious trend in patient comorbidities. While one of the specimens was collected from a lower extremity skin ulcer, the remaining five were collected from abscesses in different locations. Gram smears usually revealed the presence of multiple types of bacteria in the clinical specimens and the resulting cultures grew at least two different bacterial species as coisolates in all but one case (Table 1). The most common coisolates were anaerobic bacteria, but the more common skin and soft tissue infectious agent, Staphylococcus lugdunensis, was isolated in two cases. Susceptibility testing showed that all of the A. neuii isolates had low minimal inhibitory concentrations to penicillin, broader spectrum $\beta$-lactams, and vancomycin; one isolate had an $\mathrm{MIC} \geq 256 \mathrm{mg} / \mathrm{L}$ to clindamycin while the others had MICs of $\leq 0.032 \mathrm{mg} / \mathrm{L}$. Treatment of the abscesses usually involved incision and drainage followed by seven- to 18-day courses of a $\beta$-lactam, though one of the abscesses was treated with a four-week course of ciprofloxacin without drainage. None of the patients were noted to have relapses following therapy.

\section{Discussion}

Actinomyces neuii has been isolated in a wide range of clinical scenarios but has rarely been reported in the literature. There are less than 100 cases reported in the literature of $A$. neuii infections; we and others have hypothesized that dismissal as a commensal coryneform bacillus may be the reason. While there have only been scattered reports of $A$. neuii causing infection since interest in the organism was originally raised in the mid-1990s, the frequency of reports recognizing it as a pathogen has recently increased likely due to the use of advanced identification systems. Abscesses are the most common manifestation of $A$. neuii infection with more than half of the reported cases describing abscesses or infected atheromas (Table 2) $[6,17,19,22-45]$. A number of other infectious entities implicating $A$. neuii have been described, including ulcer infections, cellulitis, urinary tract infections, and prostatitis (Table 2).

There have been two reported cases of $A$. neuii chorioamnionitis, one of which resulted in neonatal sepsis after premature delivery $[19,27]$. In the latter case, the organism was isolated from multiple sites from the neonate, including the external ear canal, a gastric aspirate, and blood [27].

As demonstrated by the above case, $A$. neuii can also cause more invasive infections. There are multiple other cases of A. neuii bacteremia, various prostheses infections, two cases of chronic osteomyelitis, two cases of peritoneal dialysisassociated peritonitis, and single cases of native aortic valve endocarditis, chronic pericarditis, and lymphadenitis; interestingly, there have been multiple reports of $A$. neuii causing endophthalmitis, the majority of which occurred postoperatively (Table 2).

Intriguingly, there has been only one case reported of $A$. neuii causing a classical clinical picture of actinomycosis with recurrent breast abscesses, fistula formation, filamentous growth, and sulfur granules [23]. This is in agreement with the findings of our study, as none of the patients exhibited such findings nor did they require extended durations of antibiotic therapy.

The infections caused by $A$. neuii described in the present study were all associated with abscess formation in soft tissue except for one, which was isolated from an ankle ulcer. The latter case may not actually represent an infection, as there were no white cells in the clinical specimen. The age range of patients infected with $A$. neuii in the literature is $0-94$ years with a mean of 50 years; this is comparable with the ages of patients in this study. While reports in the literature show an almost even number of males and females acquiring $A$. neuii infections, the majority of the patients in our study were male; this is likely due to the small number of cases examined.

Previous studies found that abscesses typically included mixed anaerobic organisms and skin flora as coisolates (Table 2). This is similar to the present study in which four of six specimens grew anaerobic bacteria and one grew coagulase-negative staphylococci; as well, the patient from whom A. neuii was isolated in pure culture had Grampositive cocci seen in the direct smear, making it possible that this was also a mixed anaerobic infection from which at least one anaerobe failed to grow in culture. However, this study also had a larger variety of aerobic coisolates in specimens than was reported in previous studies. It is difficult to assess the specific role of $A$. neuii in these mixed infections, but its presence in polymicrobial abscesses makes up the vast majority of cases. Improved identification of $A$. neuii in the laboratory will undoubtedly help to clarify its role in disease.

There are few studies describing the use of MALDI-TOF MS MIS in identifying $A$. neuii. One other study showed that the VITEK MS system was able to correctly identify A. neuii to the species level in eight of 12 instances [21]. Three groups used Bruker MALDI-TOF MS MIS (Bruker, Billerica, MA, USA); two isolates were designated as A. neuii with a "secure genus, probable species identification" level of confidence $[20,30]$, while the degree of certainty in identification of the other isolate was not described [45]. Due to the limited amount of experience with either type of MALDI-TOF MS MIS, there is no current evidence that one system is superior to the other in identifying $A$. neuii.

The majority of tested isolates show susceptibility to $\beta$ lactams including penicillin $\mathrm{G}$, ampicillin, cefazolin, cefuroxime, ceftriaxone, and imipenem $[17,19,27,28,34-36,40$, $42,43]$. Other agents with in vitro activity against $A$. neuii include clindamycin, erythromycin, tetracycline, and vancomycin $[17,19,27,28,35,36,40,42]$. Fluoroquinolones (including ciprofloxacin and levofloxacin), aminoglycosides (including gentamicin and amikacin), and trimethoprimsulfamethoxazole frequently demonstrate less in vitro activity against isolates $[19,35,36,40]$.

Similar to previous studies, the isolates in the current series were generally quite susceptible to the tested antibiotics. All isolates had low MICs to penicillin, amoxicillinclavulanate, and vancomycin; only one isolate showed resistance to clindamycin.

As shown in Table 2, treatment regimens in the literature are varied and have been dictated by the type and severity of infection. In general, successful treatment regimens often involved the use of $\beta$-lactam antibiotics as well as appropriate 


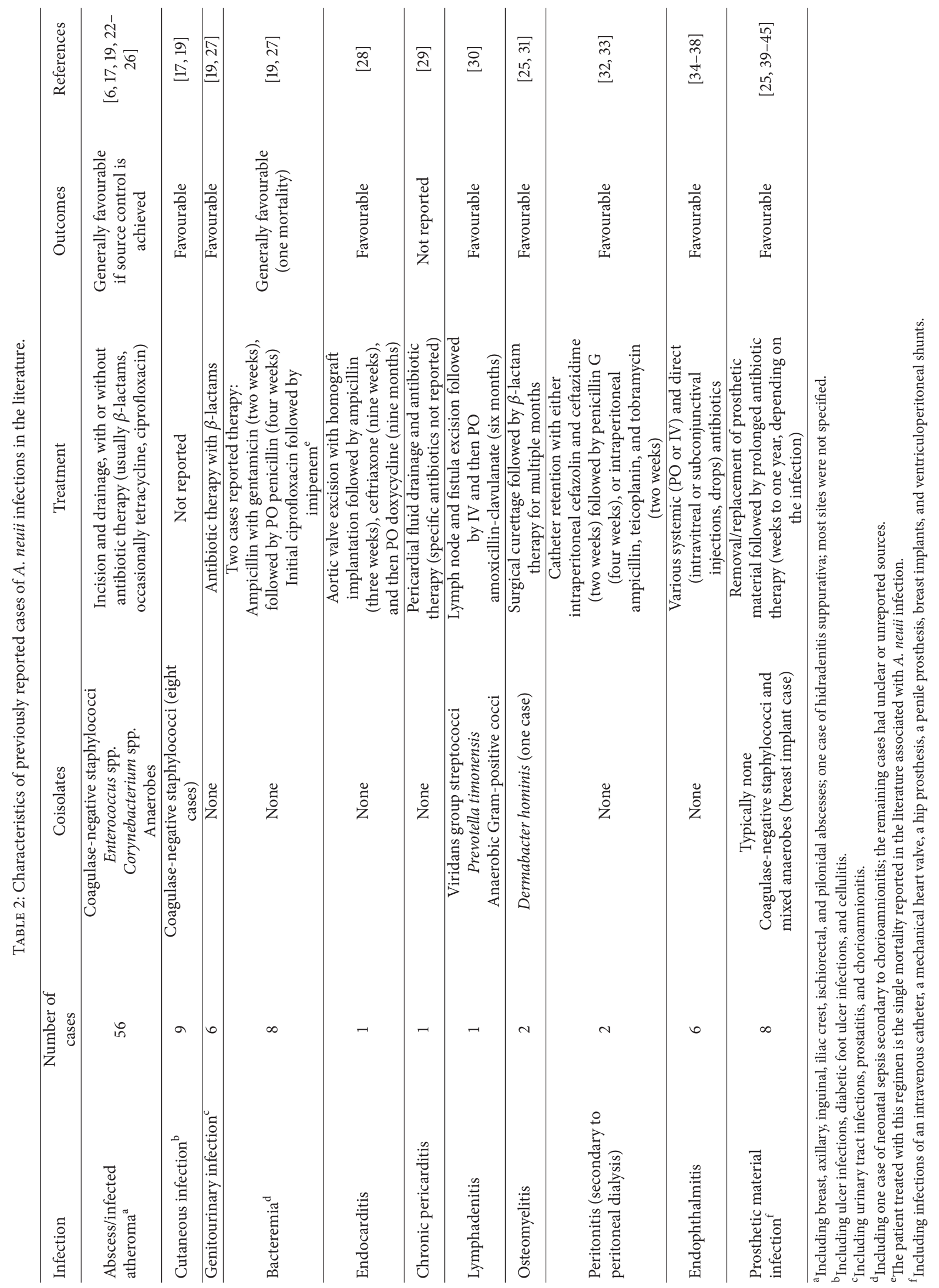


surgical interventions. This was also the case in the present study, as almost all of the treatments involved incision and drainage of abscesses with subsequent $\beta$-lactam courses.

While $A$. neuii is not a commonly identified organism, there are numerous reports of it causing both invasive and noninvasive disease. Fortunately, it is a very susceptible organism that can often be treated with $\beta$-lactams following drainage of abscesses or other surgical management. Understanding its clinical significance and typical susceptibility patterns will ease decision-making when the organism is encountered, as it surely will be with the current widespread use of MALDI-TOF MS MIS.

\section{Conflict of Interests}

The authors have no conflict of interests to declare.

\section{References}

[1] K. P. Schaal and H.-J. Lee, "Actinomycete infections in humans-a review," Gene, vol. 115, no. 1-2, pp. 201-211, 1992.

[2] R. A. Smego Jr. and G. Foglia, "Actinomycosis," Clinical Infectious Diseases, vol. 26, no. 6, pp. 1255-1263, 1998.

[3] V. K. Wong, T. D. Turmezei, and V. C. Weston, "Actinomycosis," British Medical Journal, vol. 343, Article ID d6099, 2011.

[4] L. J. M. Sabbe, D. Van De Merwe, L. Schouls, A. Bergmans, M. Vaneechoutte, and P. Vandamme, "Clinical spectrum of infections due to the newly described Actinomyces species $A$. turicensis, A. radingae, and A. europaeus," Journal of Clinical Microbiology, vol. 37, no. 1, pp. 8-13, 1999.

[5] V. Hall, P. R. Talbot, S. L. Stubbs, and B. I. Duerden, "Identification of clinical isolates of Actinomyces species by amplified $16 \mathrm{~S}$ ribosomal DNA restriction analysis," Journal of Clinical Microbiology, vol. 39, no. 10, pp. 3555-3562, 2001.

[6] J. E. Clarridge III and Q. Zhang, "Genotypic diversity of clinical Actinomyces species: phenotype, source, and disease correlation among genospecies," Journal of Clinical Microbiology, vol. 40, no. 9, pp. 3442-3448, 2002.

[7] A. S. Fiorino, "Intrauterine contraceptive device-associated actinomycotic abscess and Actinomyces detection on cervical smear," Obstetrics and Gynecology, vol. 87, no. 1, pp. 142-149, 1996.

[8] K. Westling, C. Lidman, and A. Thalme, "Tricuspid valve endocarditis caused by a new species of Actinomyces: Actinomyces funkei," Scandinavian Journal of Infectious Diseases, vol. 34, no. 3, pp. 206-207, 2001.

[9] A. Jitmuang, "Primary actinomycotic endocarditis: a case report and literature review," Journal of the Medical Association of Thailand, vol. 91, no. 6, pp. 931-936, 2008.

[10] S. Ushikoshi, I. Koyanagi, K. Hida, Y. Iwasaki, and H. Abe, "Spinal intrathecal actinomycosis: a case report," Surgical Neurology, vol. 50, no. 3, pp. 221-225, 1998.

[11] S. Wang, R. L. Wolf, J. H. Woo et al., "Actinomycotic brain infection: registered diffusion, perfusion MR imaging and $M R$ spectroscopy," Neuroradiology, vol. 48, no. 5, pp. 346-350, 2006.

[12] L. Ghafghaichi, S. Troy, I. Budvytiene, N. Banaei, and E. J. Baron, "Mixed infection involving Actinomyces, Aggregatibacter, and Fusobacterium species presenting as perispinal tumor," Anaerobe, vol. 16, no. 2, pp. 174-178, 2010.
[13] K. Imamura, H. Kamitani, H. Nakayasu, Y. Asai, and K. Nakashima, "Purulent meningitis caused by Actinomyces successfully treated with rifampicin: a case report," Internal Medicine, vol. 50, no. 10, pp. 1121-1125, 2011.

[14] E. Könönen and W. G. Wade, "Actinomyces and related organisms in human infections," Clinical Microbiology Reviews, vol. 28, no. 2, pp. 419-442, 2015.

[15] J. Versalovic, K. C. Carroll, G. Funke, J. H. Jorgensen, M. L. Landry, and D. W. Warnock, Manual of Clinical Microbiology, ASM Press, Washington, DC, USA, 2011.

[16] T. E. Na’Was, D. G. Hollis, C. W. Moss, and R. E. Weaver, "Comparison of biochemical, morphologic, and chemical characteristics of centers for disease control fermentative coryneform groups 1, 2, and A-4," Journal of Clinical Microbiology, vol. 25, no. 8, pp. 1354-1358, 1987.

[17] G. Funke, G. M. Lucchini, G. E. Pfyffer, M. Marchiani, and A. von Graevenitz, "Characteristics of CDC group 1 and group 1-like coryneform bacteria isolated from clinical specimens," Journal of Clinical Microbiology, vol. 31, no. 11, pp. 2907-2912, 1993.

[18] G. Funke, S. Stubbs, A. von Graevenitz, and M. D. Collins, "Assignment of human-derived CDC group 1 coryneform bacteria and CDC group 1-like coryneform bacteria to the genus Actinomyces as Actinomyces neuii subsp. neuii sp. nov., subsp. nov., and Actinomyces neuii subsp. anitratus subsp. nov.," International Journal of Systematic Bacteriology, vol. 44, no. 1, pp. 167-171, 1994.

[19] G. Funke and A. von Graevenitz, "Infections due to Actinomyces neuii (former 'CDC coryneform group 1' bacteria)," Infection, vol. 23, no. 2, pp. 73-75, 1995.

[20] L. S. Y. Ng, J. H. C. Sim, L. C. Eng, S. Menon, and T. Y. Tan, "Comparison of phenotypic methods and matrix-assisted laser desorption ionisation time-of-flight mass spectrometry for the identification of aero-tolerant Actinomyces spp. isolated from soft-tissue infections," European Journal of Clinical Microbiology and Infectious Diseases, vol. 31, no. 8, pp. 1749-1752, 2012.

[21] O. Garner, A. Mochon, J. Branda et al., "Multi-centre evaluation of mass spectrometric identification of anaerobic bacteria using the VITEK ${ }^{\circledR}$ MS system," Clinical Microbiology and Infection, vol. 20, no. 4, pp. 335-339, 2014.

[22] C. Lacoste, M.-C. Escande, J. Klijanienko, P. Jammet, and C. Nos, "Breast Actinomyces neuii abscess simulating primary malignancy: a case diagnosed by fine-needle aspiration," Diagnostic Cytopathology, vol. 37, no. 4, pp. 311-312, 2009.

[23] A. Roustan, M. Al Nakib, and L. Boubli, "Primary actinomycosis of the breast due to Actinomyces neuii," Journal de Gynecologie Obstetrique et Biologie de la Reproduction, vol. 39, no. 1, pp. 64-67, 2010.

[24] J. L. Gómez-Garcés, A. Burillo, Y. Gil, and J. A. Sáez-Nieto, "Soft tissue infections caused by Actinomyces neuii, a rare pathogen," Journal of Clinical Microbiology, vol. 48, no. 4, pp. 1508-1509, 2010.

[25] K. De Vreese and J. Verhaegen, "Identification of coryneform Actinomyces neuii by MALDI-TOF MS: 5 case reports and review of literature," Acta Clinica Belgica, vol. 68, no. 3, pp. 210214, 2013.

[26] J. M. Olson and J. C. Vary Jr., "Primary cutaneous Actinomyces neuii infection of the breast successfully treated with doxycycline," Cutis, vol. 92, no. 6, pp. E3-E4, 2013.

[27] C. Mann, S. Dertinger, G. Hartmann, R. Schurz, and B. Simma, "Actinomyces neuii and neonatal sepsis," Infection, vol. 30, no. 3, pp. 178-180, 2002. 
[28] E. Cohen, J. Bishara, B. Medalion, A. Sagie, and M. Garty, "Infective endocarditis due to Actinomyces neuii," Scandinavian Journal of Infectious Diseases, vol. 39, no. 2, pp. 180-183, 2007.

[29] P.-Y. Levy, P.-E. Fournier, R. Charrel, D. Metras, G. Habib, and D. Raoult, "Molecular analysis of pericardial fluid: a 7-year experience," European Heart Journal, vol. 27, no. 16, pp. 19421946, 2006.

[30] K. Walther, E. Bruder, D. Goldenberger, J. Mayr, U. B. Schaad, and N. Ritz, "Actinomyces neuii isolated from a 20-monthold girl with cervical lymphadenitis," Journal of the Pediatric Infectious Diseases Society, vol. 4, no. 3, pp. e32-e37, 2015.

[31] B. Van Bosterhaut, P. Boucquey, M. Janssens, G. Wauters, and M. Delmée, "Chronic osteomyelitis due to Actinomyces neuii subspecies neuii and Dermabacter hominis," European Journal of Clinical Microbiology and Infectious Diseases, vol. 21, no. 6, pp. 486-487, 2002.

[32] S. Varughese and J. Bargman, "Actinomyces neuii PD peritonitis-resolution of infection without catheter removal," Peritoneal Dialysis International, vol. 34, no. 7, pp. 815-816, 2014.

[33] R. Díaz, M. A. Bajo, G. Del Peso, A. García-Perea, R. SánchezVillanueva, and R. Selgas, "Actinomyces peritonitis: removal of the peritoneal catheter unnecessary for resolution," NDT Plus, vol. 3, no. 3, pp. 296-297, 2010.

[34] P. E. Coudron, R. C. Harris, M. G. Vaughan, and H. P. Dalton, "Two similar but atypical strains of coryneform group A-4 isolated from patients with endophthalmitis," Journal of Clinical Microbiology, vol. 22, no. 4, pp. 475-477, 1985.

[35] J. M. Garelick, A. J. Khodabakhsh, and R. G. Josephberg, "Acute postoperative endophthalmitis caused by Actinomyces neuii," American Journal of Ophthalmology, vol. 133, no. 1, pp. 145-147, 2002.

[36] V. S. Raman, N. Evans, B. Shreshta, and R. Cunningham, "Chronic postoperative endophthalmitis caused by Actinomyces neuii," Journal of Cataract and Refractive Surgery, vol. 30, no. 12, pp. 2641-2643, 2004.

[37] J. J. Pérez-Santonja, E. Campos-Mollo, E. Fuentes-Campos, J. Samper-Giménez, and J. L. Alió, "Actinomyces neuii subspecies anitratus chronic endophthalmitis after cataract surgery," European Journal of Ophthalmology, vol. 17, no. 3, pp. 445-447, 2007.

[38] S. Graffi, A. Peretz, and M. Naftali, "Endogenous endophthalmitis with an unusual infective agent: Actinomyces neuii," European Journal of Ophthalmology, vol. 22, no. 5, pp. 834-835, 2012.

[39] S. Brunner, S. Graf, P. Riegel, and M. Altwegg, "Catalasenegative Actinomyces neuii subsp. neuii isolated from an infected mammary prosthesis," International Journal of Medical Microbiology, vol. 290, no. 3, pp. 285-287, 2000.

[40] R. R. Watkins, K. Anthony, S. Schroder, and G. S. Hall, "Ventriculoperitoneal shunt infection caused by Actinomyces neuii subsp. neuii," Journal of Clinical Microbiology, vol. 46, no. 5, pp. 1888-1889, 2008.

[41] H. Rieber, R. Schwarz, O. Krämer, W. Cordier, and L. Frommelt, "Actinomyces neuii subsp. neuii associated with periprosthetic infection in total hip arthroplasty as causative agent," Journal of Clinical Microbiology, vol. 47, no. 12, pp. 4183-4184, 2009.

[42] S. Grundmann, J. Huebner, J. Stuplich et al., "Prosthetic valve endocarditis due to Actinomyces neuii successfully treated with antibiotic therapy," Journal of Clinical Microbiology, vol. 48, no. 3, pp. 1008-1011, 2010.

[43] R. S. Hsi, J. M. Hotaling, E. S. Spencer, P. L. Bollyky, and T. J. Walsh, "Isolated infection of a decommissioned penile prosthesis reservoir with Actinomyces neuii," Journal of Sexual Medicine, vol. 8, no. 3, pp. 923-926, 2011.

[44] I. A. Anderson, F. Jarral, K. Sethi, and P. D. Chumas, "Paediatric ventriculoperitoneal shunt infection caused by Actinomyces neuii," BMJ Case Reports, 2014.

[45] P. Seng, S. Bayle, A. Alliez, F. Romain, D. Casanova, and A. Stein, "The microbial epidemiology of breast implant infections in a regional referral centre for plastic and reconstructive surgery in the south of France," International Journal of Infectious Diseases, vol. 35, pp. 62-66, 2015.

[46] D. J. Lane, "16S/23S rRNA sequencing," in Nucleic Acid Techniques in Bacterial Systematics, E. Stackebrandt and M. Goodfellow, Eds., pp. 115-175, John Wiley \& Sons, Chichester, UK, 1991.

[47] J. R. Cole, Q. Wang, J. A. Fish et al., "Ribosomal Database Project: data and tools for high throughput rRNA analysis," Nucleic Acids Research, vol. 42, no. 1, pp. D633-D642, 2014.

[48] Clinical and Laboratory Standards Institute, "Performance standards for Antimicrobial Susceptibility Testing; 25th informational supplement," Tech. Rep. M100-S25, Clinical and Laboratory Standards Institute, 2015.

[49] Canadian Institutes of Health Research, Natural Sciences, and Engineering Research Council of Canada, and Social Sciences and Humanities Research Council of Canada, "Tri-Council Policy Statement: Ethical Conduct for Research Involving Humans," December 2014. 


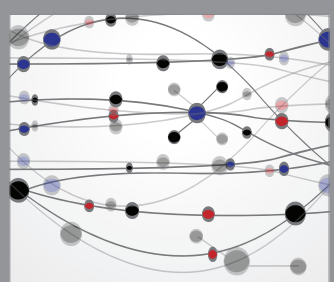

The Scientific World Journal
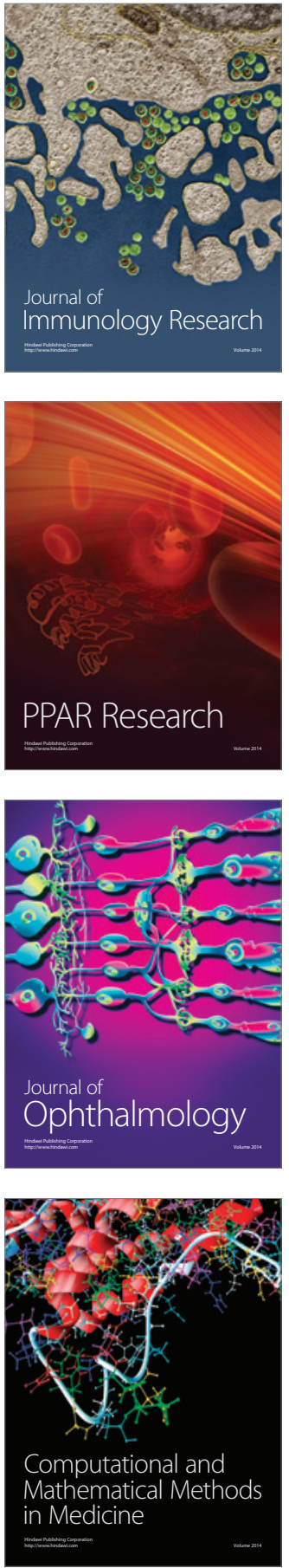

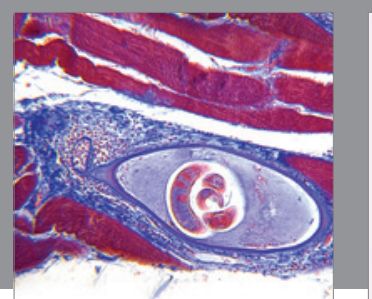

Gastroenterology Research and Practice

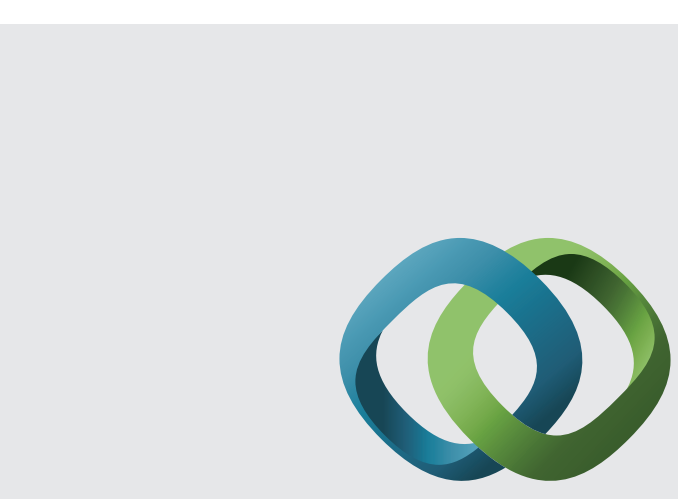

\section{Hindawi}

Submit your manuscripts at

http://www.hindawi.com
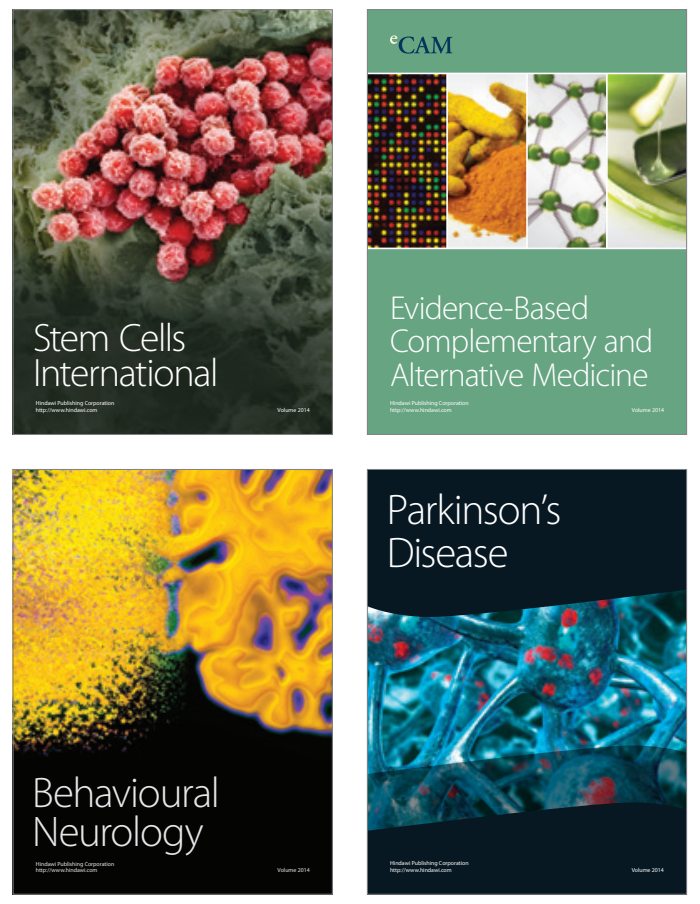
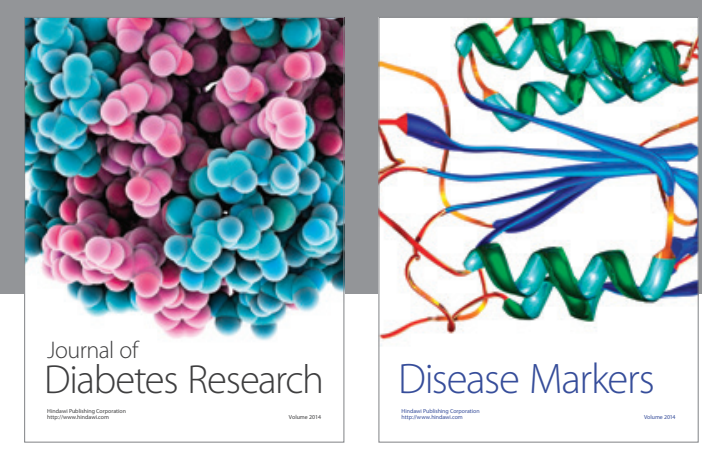

Disease Markers
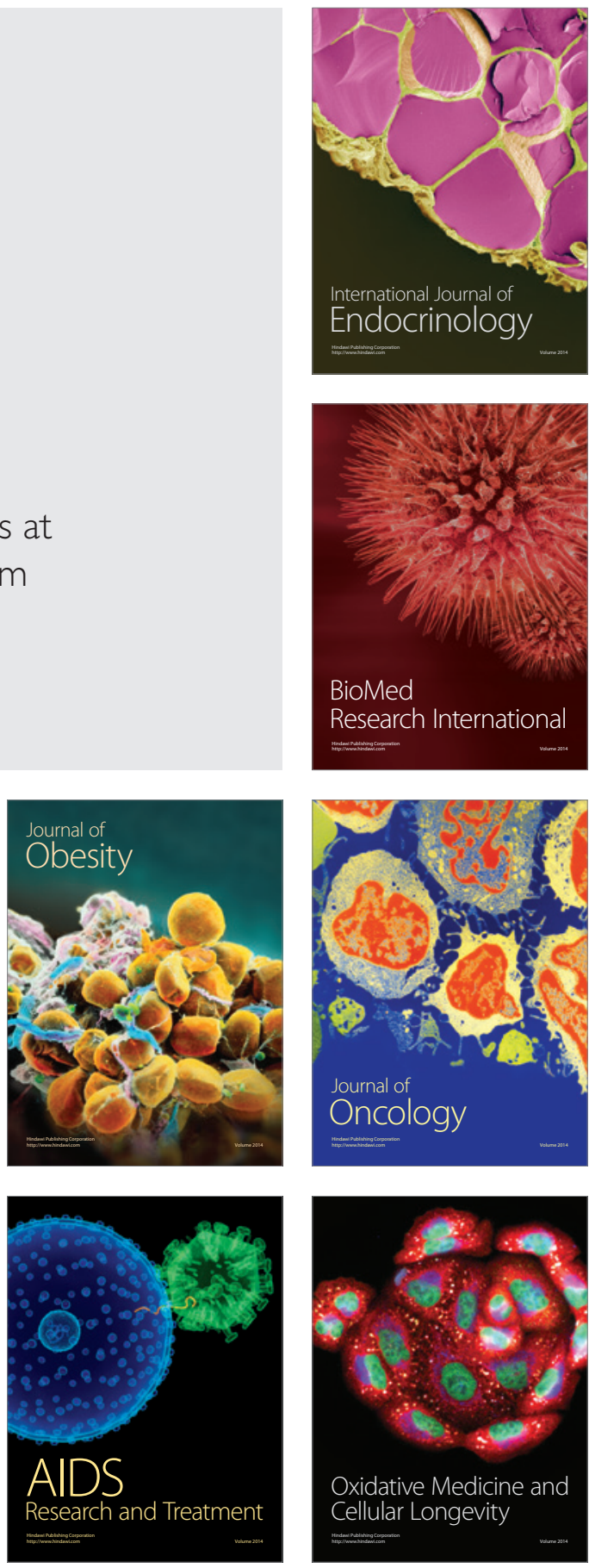